\title{
Differential mortality patterns from hydro-meteorological disasters: Evidence from cause-of-death data by age and sex
}

\author{
Emilio Zagheni, Raya Muttarak and Erich Striessnig*
}

\begin{abstract}
This paper evaluates the heterogeneous impact of hydro-meteorological disasters on populations along the dimensions of age, sex, and human development. The analysis is based on previously untapped cause-of-death data over the period 19952011 that were obtained from the WHO mortality database, and were based on the civil registration records of 63 countries/territories. Using these data, we evaluate patterns of mortality related to meteorological disasters in the spirit of model life tables. We observe that mortality rates from hydro-meteorological disasters for men are consistently higher than for women across all age groups, and that the differential by sex is larger for adults than for young children or the elderly. Furthermore, the sex differential in mortality becomes smaller with improvements in human development. Comparing our disaster fatalities with those recorded in the Emergency Events Database (EM-DAT), we find that the number of deaths from hydro-meteorological disasters was underestimated in the WHO database, especially in the case of highimpact events. In the paper we discuss issues of data quality and data harmonisation for the study of the differential demographic impact of natural disasters. One of our main goals is to stimulate an interdisciplinary debate in this area.
\end{abstract}

* Emilio Zagheni, Department of Sociology and eScience Institute, University of Washington, Seattle, USA

Raya Muttarak, Wittgenstein Centre for Demography and Global Human Capital (IIASA, VID/ÖAW, WU), International Institute for Applied Systems Analysis (IIASA), Vienna Institute of Demography, Austrian Academy of Sciences, Vienna, Austria

Erich Striessnig (corresponding author), Wittgenstein Centre for Demography and Global Human Capital (IIASA, VID/ÖAW, WU), International Institute for Applied Systems Analysis (IIASA), Vienna Institute of Demography, Austrian Academy of Sciences, Vienna, Austria

Email: striess@iiasa.ac.at

All authors contributed equally to formulating the research design, analysing the data, and writing and revising the manuscript. 


\section{Introduction}

There is evidence that both the frequency and the intensity of extreme weather events, such as storms, floods, and droughts, have been increasing in recent decades (IPCC 2007), with floods being the most common type of natural disaster worldwide. In addition to having severe effects on livelihoods, property, and the economy; floods cause very large numbers of fatalities. Flooding is most commonly caused by heavy rainfall or by other weather events; in coastal areas in particular, flooding is often caused by storm surges associated with tropical cyclones. During the past three decades, up to 230,000 deaths worldwide have been attributed to floods, while an estimated 447,000 deaths have been linked to storms, particularly tropical cyclones (EM-DAT 2010). Although the death toll from individual flood or storm events is generally lower than it is from other destructive disaster events, like mega-earthquakes or tsunamis, the frequency of disasters resulting from floods and storms has increased in recent decades. Accordingly, in 2012 hydrometeorological disasters were responsible for the largest share of natural disaster fatalities, accounting for $39 \%$ of global disaster mortality in that year (Guha-Sapir et al. 2013).

At first glance, the risk of death from storms and floods would appear to depend on their meteorological characteristics (e.g. the speed of onset, the scale, the duration, the velocity of the flow, and the depth of the water). However, the topography of the area, the land-use patterns, and the antecedent moisture conditions also matter (Ahern et al. 2005). In addition to geophysical characteristics, the level of economic development has been found to be significant in determining human and economic losses from natural disasters (Fankhauser and McDermott 2014; Toya and Skidmore 2007). Compared to more developed countries, developing countries generally suffer much higher death tolls from floods and cyclones because they often have poor infrastructure and badly constructed housing, high-density settlements, a lack of early warning systems, and poorly devised evacuation and shelter procedures (Doocy et al. 2013a). The fact that most deaths from cyclones in less developed nations are storm surge drowning fatalities that occur during the impact phase implies that deaths from storms are, to a certain degree, preventable (Shultz et al. 2005).

Likewise, it has been shown that flood- and storm-related mortality is not distributed evenly across population subgroups. Gender, age, ethnicity, and socioeconomic status are reported to be associated with the risk of mortality from hydrometeorological disasters. While most studies have found that the elderly are more vulnerable to floods (Jonkman et al. 2009; Myung and Jang 2011; Thacker et al. 2008), it has also been reported that very young children, especially in low-income countries, have higher flood-related mortality (Pradhan et al. 2007). Similarly, for storm-related deaths, both children and older adults are exposed disproportionately to higher mortality risks (Brunkard et al. 2008; Bern et al. 1993; Chowdhury et al. 1993). With respect to gender, in developed countries men are generally more likely to die from flood- and storm-related causes, whereas in less developed countries 
women appear to have a higher risk of mortality (Alderman et al. 2012; Doocy et al. 2013a, 2013b). In addition, studies have shown that flood-related mortality in different age groups is not distributed evenly between men and women: while the vast majority of females who die in floods are elderly women (Coates 1999), in many countries flood-related deaths are most common among adult men (Ashley and Ashley 2008; Coates 1999). Gender differences in risk-taking behaviours may account for observed differences in the mortality outcomes of men and women in certain types of natural disasters (Kruger and Nesse 2004).

Given that demographic characteristics play a significant role in determining risk exposure levels during hydro-meteorological disasters, identifying who is more likely to perish during floods and storms would allow for the implementation of appropriate risk reduction measures that target the relevant vulnerable groups. The existing empirical studies of demographic differentials in disaster-related mortality are, however, overwhelmingly based on hazard events in the United States (Ashley and Ashley 2008; Jonkman et al. 2009; Jonkman and Kelman 2005; Thacker et al. 2008) and a few other developed countries (FitzGerald et al. 2010; Coates 1999). The literature on age-sex differences in disaster-related fatalities in developing countries, where mortality registration systems often underreport deaths or are not widely available, is scarce. Likewise, there are only a few cross-national studies on demographic differential mortality from natural disasters that include both developed and less developed nations. In addition, most of the existing studies on the impacts of economic development on the scale of loss and damage from natural disasters do not consider how the level of development affects different population subgroups.

Accordingly, our aim in this study is to (1) estimate the impact of hydrometeorological disasters (i.e. floods and storms) on mortality among different population subgroups, and (2) investigate the relationship between development and age-sex differences in reducing fatalities from hydro-meteorological disasters. We use a mostly untapped resource in the disaster literature: i.e. cause-of-death data by age and sex from the WHO (World Health Organization) Mortality Database. The estimation of hydro-meteorological disaster deaths from the WHO data is then validated with the commonly used disaster data source, the Emergency Events Database (EM-DAT). Principal component analysis is employed to describe agesex patterns in mortality from floods and storms across 63 countries/territories from 1995 to 2011. Using this approach, we are able to describe age-sex mortality profiles related to hydro-meteorological disasters for many countries at the same time.

Furthermore, a first-difference approach is employed to estimate how changes in the level of development (measured by the Human Development Index) relate to changes in the mortality rates of men and women in different age groups. This identification of patterns of disaster-related mortality by age, sex, and level of development is particularly important, as understanding these patterns could help us anticipate the extent to which future societies will be able to cope with natural disasters as their demographic compositions and levels of socio-economic development change. 
The remainder of the paper is organised as follows. In Section 2 we describe the data used for the analysis, while in Sections 3 and 4 we present the methods and the results. We first show the results from the WHO data, and then present a validation of our analysis by comparing our findings with the numbers of deaths from hydrometeorological disasters reported by the EM-DAT. In Section 5 we discuss potential further uses of the WHO data, as well as the value of the kinds of analyses we performed. We close with a discussion and a summary of our results.

\section{Data}

\subsection{Cause-of-death data by age and sex}

To perform our analysis, we needed information on cause-specific mortality by age and sex. We identified a data source that has been almost untapped in the disaster literature: i.e. death registrations by age, sex, and cause of death. The data are published in a harmonised format by the WHO, which gathers vital statistics from civil registration systems submitted to the WHO annually by the national authorities of member countries. The database goes as far back as 1950. Numbers of deaths by country, year, sex, age group, and cause of death are provided. Causes of death are classified according to the International Classification of Diseases (ICD), a system of diagnostic codes developed to classify diseases and categorise medical terms reported by physicians and coroners on death certificates for international compatibility and statistical purposes. The most up-to-date revision of the ICD classification is ICD-10, which has been used by WHO member states since 1994. The data are freely available for download online via the WHO mortality database website. ${ }^{1}$

Disaster-related deaths are classified in ICD-10 under the label 'exposure to forces of nature'. This broad category includes deaths related to excessive natural heat or cold, earthquakes, volcanic eruption, landslides, etc. In the current study we consider two groups of causes, 'cataclysmic storm' (code X37) and 'flood' (code $\mathrm{X} 38$ ), which are natural hazards that are likely to become more common and more severe due to climate change (Nicholls 2004). These two categories include deaths that are both directly and indirectly related to hurricanes, storms, floods, tornadoes, and tidal waves. Direct mortality from floods and storms refers to deaths caused by the environmental force of a disaster (e.g. a storm surge, wind, and flooding). Indirect mortality refers to deaths attributable to unsafe conditions caused by a disaster (e.g. electrocutions from downed power lines and hazardous roads) or by a loss or a disruption of usual services caused by a disaster (e.g. loss of electrical services). We have data on mortality from 'cataclysmic storm' and 'flood' for 63 countries/territories for the period 1995-2011. Figure 1 shows a map of countries

1 http://www.who.int/healthinfo/mortality_data/en/ 
Figure 1:

Map of countries where data on causes of death related to 'cataclysmic storm' (X37) and 'flood' (X38) are available in WHO ICD-10 (1995-2011)

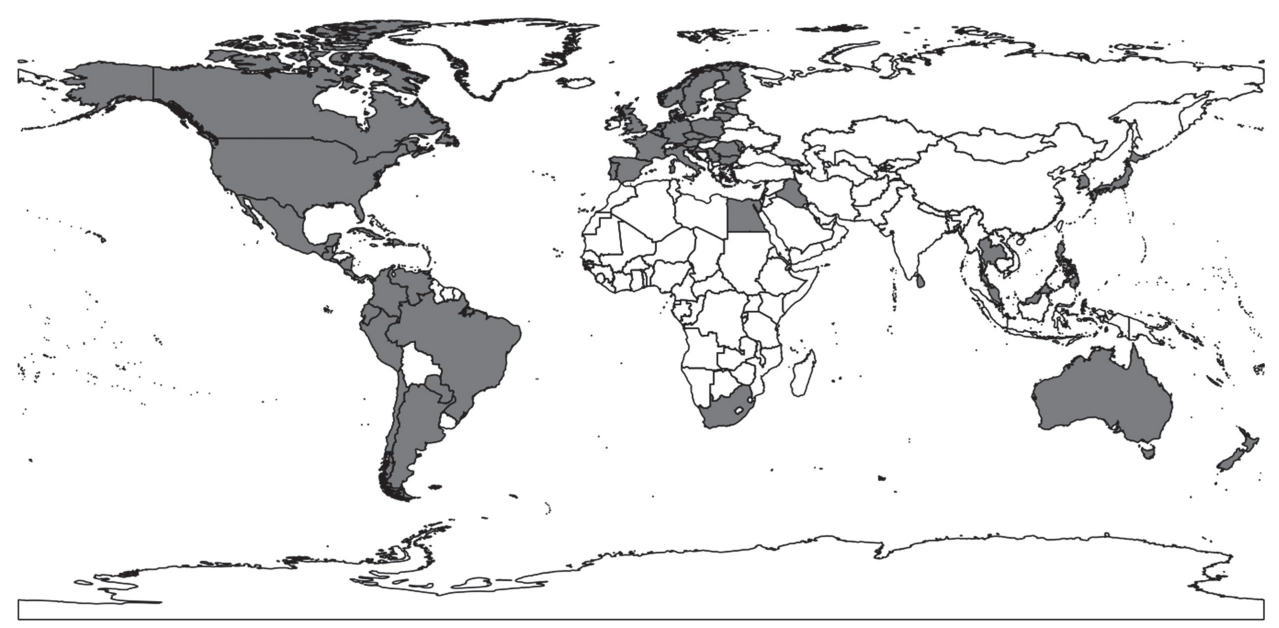

for which data are available in ICD-10. The sample is skewed towards high-income countries that have efficient vital registration systems and most countries in Latin America. However, a few developing countries in southeast Asia and Africa are also included.

\subsection{Mortality from natural disasters data}

Maintained by the Centre for Research on the Epidemiology of Disasters (CRED) since 1988, the Emergency Events Database (EM-DAT) is a database that has been compiled specifically to monitor disasters worldwide. In addition to having data on disasters that have occurred across the world from 1900 to the present, the EM-DAT also contains information on loss and damage, including the number of people killed and the number of people affected in a particular disaster. The data are collected from various sources, with priority given to data from UN agencies, followed by data from the Office of U.S. Foreign Disaster Assistance (OFDA), national governments, and the International Federation of Red Cross and Red Crescent Societies. An event qualifies as a disaster and is included in the EM-DAT database if it fulfils at least one of the following criteria: 1) 10 or more people are reported killed, 2) 100 or more people are reported affected, 3) the government declares a state of emergency, or 4) the government appeals for international assistance.

While both natural disasters and technological disasters are recorded in the EM-DAT, here we focus only on mortality from hydro-meteorological disasters, i.e. floods and storms. This allows us to compare deaths from floods and storms registered in the WHO data with those in the EM-DAT data for each country. 


\section{Patterns of flood and cataclysmic storm mortality}

\subsection{Methods}

We identify patterns of mortality by age and sex from cataclysmic storms (X37) and floods (X38) using data from the WHO database. Our method is based on classic demographic approaches developed in the context of model life tables. We use an approach inspired by the Lee and Carter (1992) model for forecasting mortality in the United States and the model life table system for sub-Saharan Africa (INDEPTH Network 2004). Since we are interested in the distribution of deaths related to storms and floods by age for each sex respectively, we subtract the average profile of deaths by age for all countries from the number of deaths for a given age group $a$ during the year $t$ for each geographic region among all of the 63 countries/territories in the ICD-10 database. We then model this quantity as the product of age-specific profiles and time-variant indexes:

$$
D_{(a, t)}^{i}-D_{(a, t)}=B_{1(a)} k_{1(t)}+B_{2(a)} k_{2(t)}+B_{3(a)} k_{3(t)}+e
$$

where $D_{(a, t)}^{i}$ is the number of deaths related to hydro-meteorological disasters in country $i$, for age group $a$, during year $t . D_{(a, t)}$ is the average number of deaths related to hydro-meteorological disasters for age group $a$, during year $t$, across all countries considered. $B_{1(a)}, B_{2(a)}$, and $B_{3(a)}$ are vectors of age profiles of deaths associated with the first, the second, and the third principal components of the demeaned death data, respectively. $k_{1(t)}, k_{2(t)}$ and $k_{3(t)}$ are vectors of time trends.

In order to estimate the $B$ and $k$ terms, we use Principal Component Analysis (PCA), which is equivalent to a Singular Value Decomposition (SVD) on the demeaned profiles of deaths by age and sex for all countries in the dataset. The goal is to summarise the available data in order to extract meaningful information about profiles by age for the available countries. The analysis is done for men and women separately. Our approach is consistent with a long history of demographic modelling of age schedules. For a detailed explanation of the estimation procedure, the relationship between SVD and PCA, as well as a presentation of a number of demographic applications, see Clark (2015).

We decided to use the first three principal components, as they explain a relatively large proportion of the variance $(\sim 50 \%)$ in the observed profiles, and allow for a simple demographic interpretation. Including more components would explain a larger proportion of the variance, but would not provide additional insights. We thus decided to use a relatively parsimonious model. The main reason why the first principal components do not explain a larger portion of the variance is that because disasters are relatively rare phenomena, the data contain a large number of agecountry-year combinations with zero deaths. As a result, the overall variance of the data points is quite large. In other words, the data are very noisy, and for a number of countries we may observe spikes in the number of deaths due to a single event, followed by several years of very low death counts. 
Figure 2:

First three principal components of demeaned number of deaths related to floods and cataclysmic storms for females. Dashed lines represent smoothed values
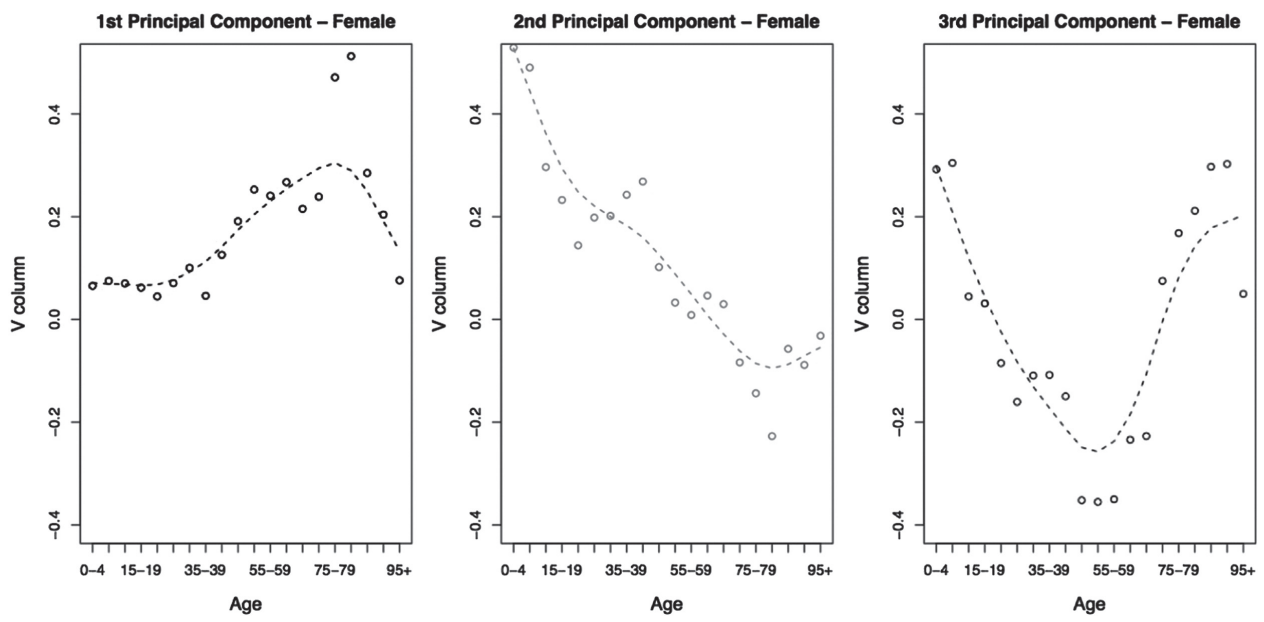

Source: Own calculations based on ICD-10, WHO mortality database.

\subsection{Results}

Figure 2 shows the first three principal components of the demeaned number of deaths related to floods and cataclysmic storms for females. The first component indicates a death profile by age that is strongly skewed towards the elderly. The second component is skewed towards young children. The third component emphasises this bimodal distribution of deaths by having negative values for observations for adults and positive values for children and the elderly.

Figure 3 shows the first three principal components of the demeaned number of deaths related to floods and cataclysmic storms for males. The first component shows that storm- and flood-related mortality for males spreads out rather evenly across age groups. The second component is moderately skewed towards very young children. The third component reveals a relatively large number of deaths for adult males that are not observed for females.

The mortality profiles by age differ considerably between men and women. While the three principal components for females together show that most deaths from floods and storms typically occur among young girls and elderly women, the male death profile shows a somewhat different pattern, with mortality being higher among adolescent and adult males. This bump in the number of deaths among male adults may be attributable to a greater proneness to risky behaviour or a lower ability to assess risks among males than among females (Byrnes et al. 1999; Croson and Gneezy 2009). In addition, because men are more likely than women to engage in outdoor work and leisure activities, they are more exposed to natural hazards, such as flood and storm events. 
Figure 3:

First three principal components of demeaned number of deaths related to floods and cataclysmic storms for males. Dashed lines represent smoothed values
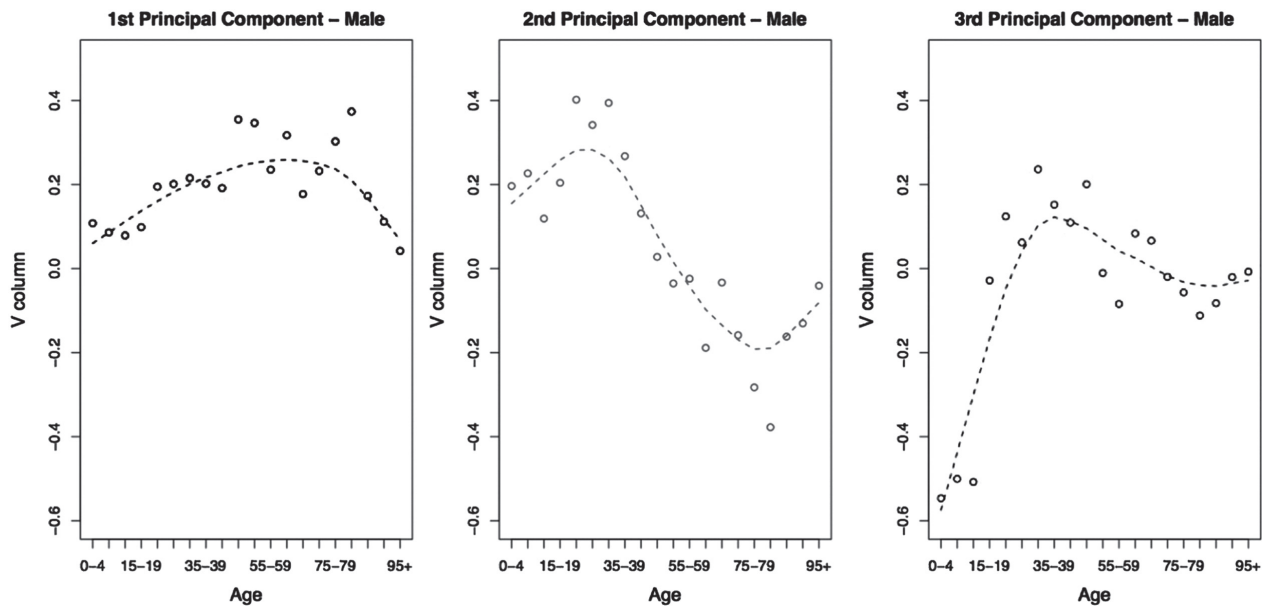

Source: Own calculations based on ICD-10, WHO mortality database.

The first three principal components account for more than $50 \%$ of the variance in the data and capture the key summary profiles of mortality from floods and storms for men and women. The observations have very high levels of variance because of the nature of disaster data. For some countries, we observe only a small number of deaths over the course of several years, resulting in a large number of age-specific cells that contain zeroes. The additional principal components explain the remaining variance due to the large number of zeroes in the data, but do not have any relevant structure, and do not add much information to our analysis.

We also evaluated the first three principal components of death rates in addition to looking at death counts. When we consider mortality rates, the results are qualitatively similar. However, a larger proportion of the variance is explained by a first principal component that captures old-age mortality for both men and women. The combination of high disaster death counts among the elderly with relatively small population sizes for older age groups leads to an increased emphasis on oldage mortality. Ideally, we would have data on deaths and the numbers of people exposed to risk. We do not, however, have that information; we only have data on country-level population size by age and sex, as available from the World Population Prospects: the 2012 Revision (United Nations 2013). Thus, even major events like Hurricane Katrina may have small effects on mortality rates when the denominator is the entire U.S. population. Likewise, relatively small floods or storms may have large effects on the mortality rates of small countries, even when the death counts are not high. Death counts and death rates have different advantages and disadvantages in the context of our analysis. In this section, we emphasised results based on death counts. In the next section, we will look more closely at death rates. 


\section{Gender differences in mortality from floods and storms}

The principal component analysis indicates that there are substantial differences in the age-specific mortality profiles of men and women. However, the PCA does not allow us to quantify whether men have higher or lower mortality rates from floods and storms than women. In the subsequent analysis, we therefore compare the age-specific mortality rates from hydro-meteorological disasters of men and women for each country over the period 1995-2011. Figure 4 presents the results from selected countries that represent the general patterns of hydro-meteorological disasters by age and sex, in terms of both death distribution and death rates per 1000 of population.

Countries in which a higher proportion of the population are elderly, such as South Korea, Japan (not shown), and the United States, show a monotonic increase in mortality with age. Most of the deaths occur among adults or the elderly, with more male fatalities occurring among the older age groups in particular. Paraguay, Nicaragua, and Cuba (not shown) are examples of the second pattern, in which the highest mortality rates and the largest numbers of deaths are among male adults. In Argentina, the Philippines, Mexico, Brazil, and Guatemala (not shown), the largest numbers of deaths from the hydro-meteorological disasters are, in absolute terms, of young children. In Argentina, Mexico, and Brazil, the mortality rates are higher among young children and the elderly, especially females. But in the Philippines and Guatemala, which have young population age structures, the mortality rates for young children are not very high, even though the largest numbers of deaths are, in absolute terms, of children.

Turning to gender differences in fatalities from floods and storms for all countries with $\geq 10$ deaths over the period 1995-2011, as presented in Figure 5, we find that in most countries the absolute number of deaths is larger for males than for females. Men might be more vulnerable to flood- and storm-related mortality than women because they generally exhibit more risky behaviours and engage in more dangerous activities than women. Note that for most countries, the number of deaths from floods and storms does not exceed 200 in the period observed. However, in tropical cyclone-prone areas such as Mexico, Japan, the Philippines, and the United States, the numbers of registered deaths from floods and storms are large, and male mortality levels are always higher than female mortality levels.

\section{Meteorological disaster mortality and development}

Having found evidence for a gender difference in mortality from hydrometeorological disasters, we examine the question of whether the observed reduction in loss of life due to economic development follows the same patterns for men and women and for different age groups. Development is measured by the UNDP Human Development Index (HDI), a composite index of life expectancy, educational levels, and economic prosperity. In order to have a larger sample that 
Figure 4:

Profiles of flood and cataclysmic storm mortality for selected countries, by age and sex. The bubbles indicate mortality rates $(\times 1000)$. The size of the bubbles is proportional to the actual number of deaths and has been rescaled for each country separately. Thus, comparisons of number of deaths across countries, based on the size of the bubbles, are not possible. The solid lines are the smoothed values
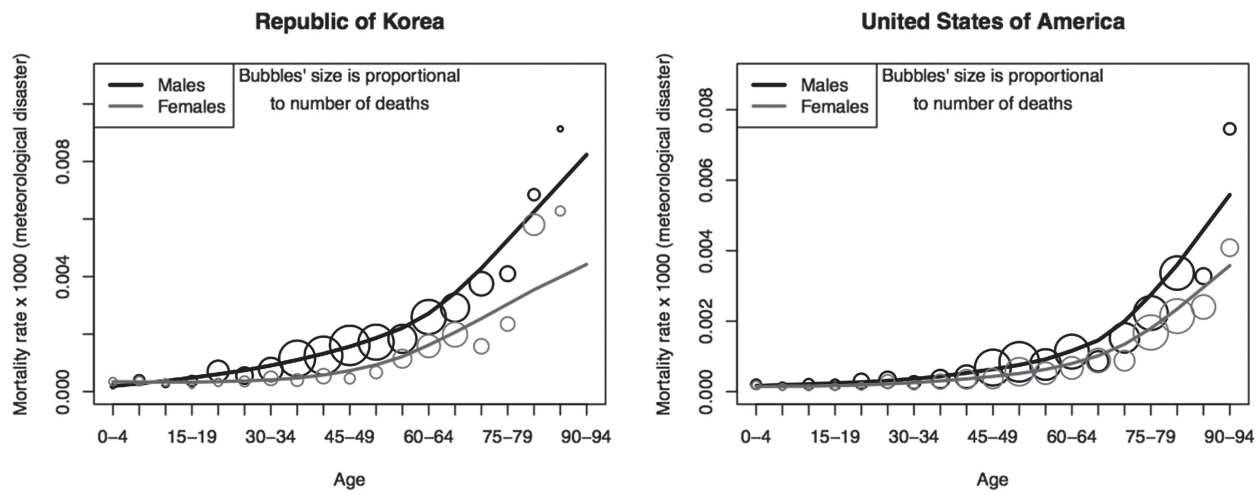

Paraguay
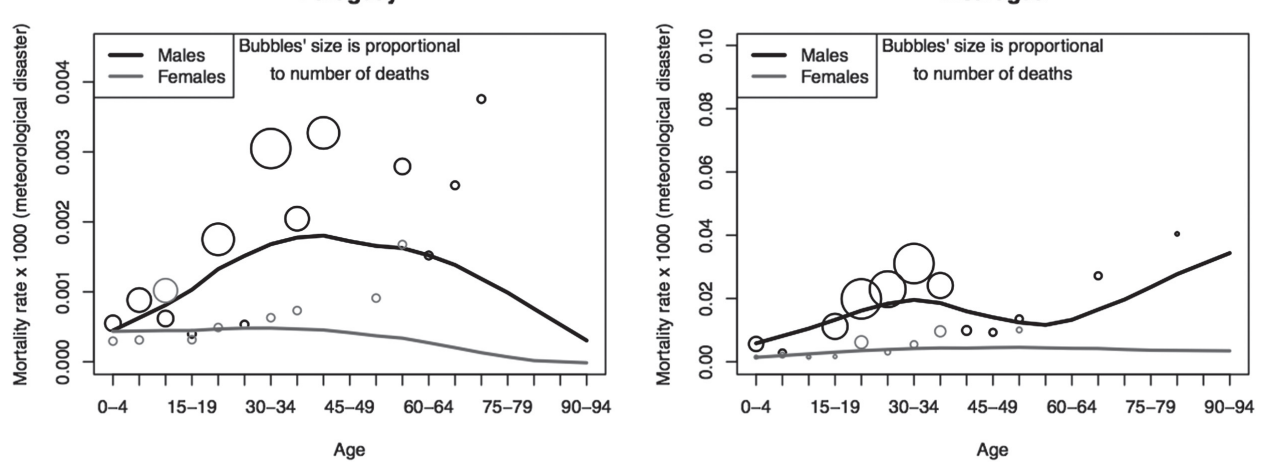

Argentina
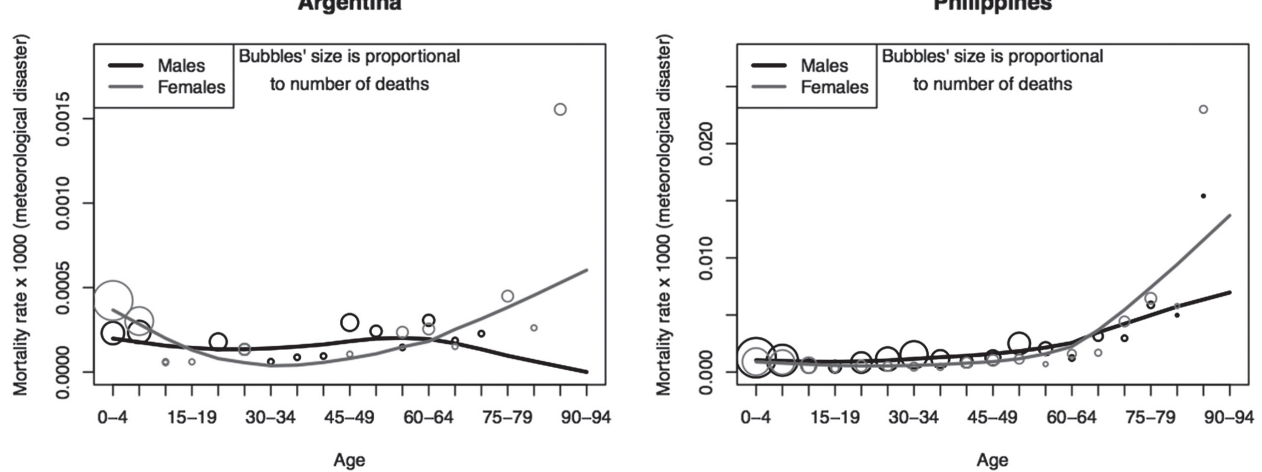

Source: Own calculations based on ICD-10 WHO mortality database (for death counts) and UN WPP 2012 (for population counts). 
Figure 5:

Total number of deaths from floods and storms by gender for selected countries with $\geq 10$ deaths over the period 1995-2011

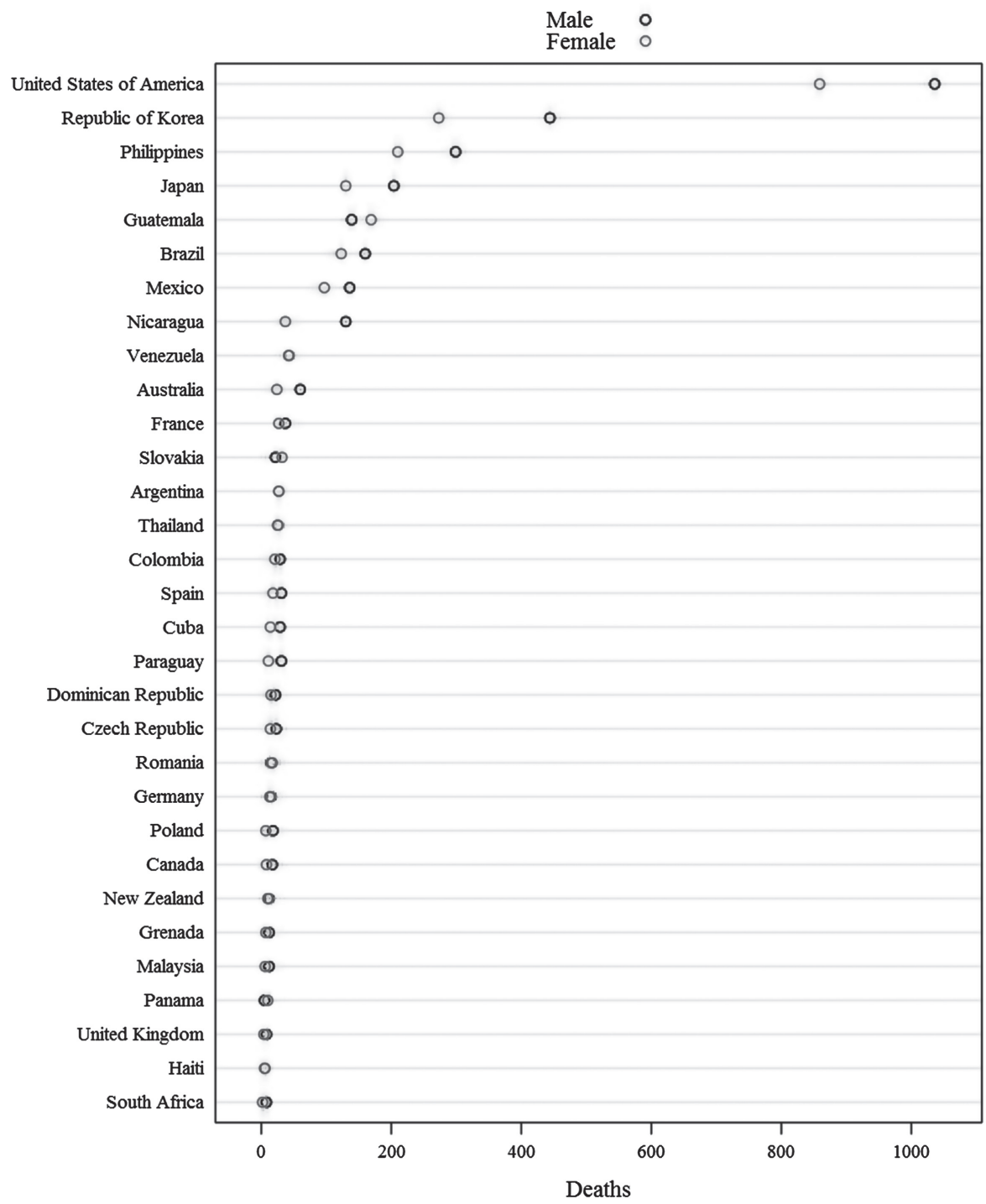

Source: Own calculations based on ICD-10 WHO mortality database.

covers a longer time period than the ICD-10 data alone can provide, we include data from three previous classifications: ICD-7, ICD-8, and ICD-9. Those datasets extend as far back as 1970. However, in the older versions of the ICD, deaths related to cataclysmic storms or floods were not classified with a specific code. Thus, we select causes of death potentially related to meteorological disasters; i.e. 
Figure 6:

Relationship between meteorological disaster mortality and Human Development Index, by age and sex
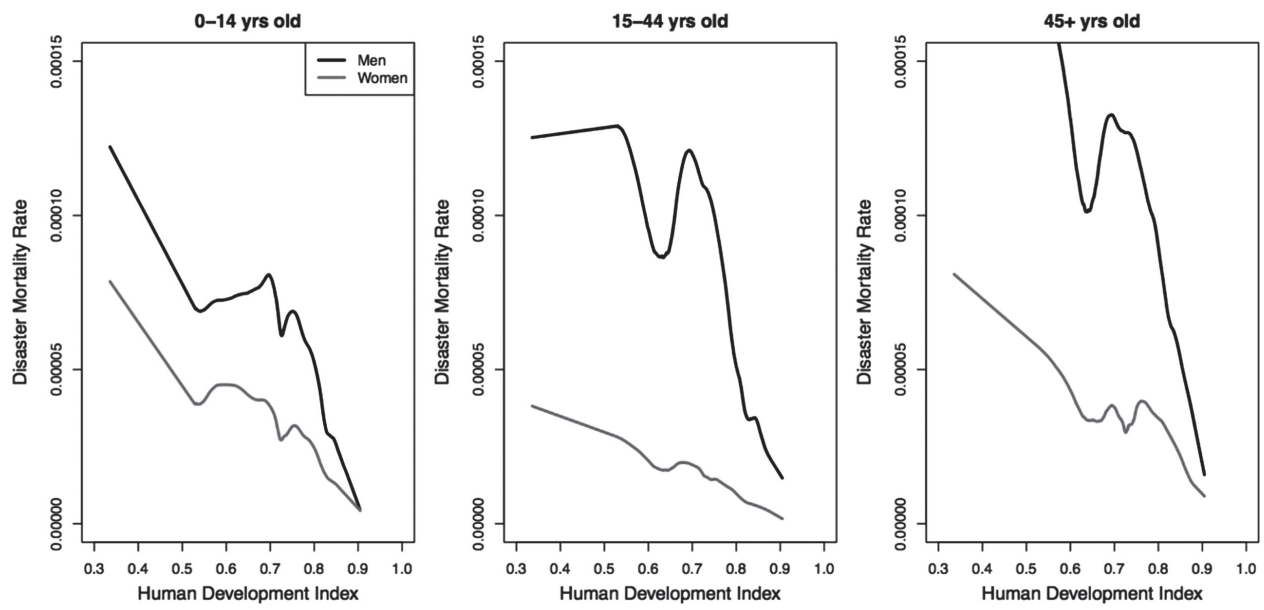

'accidental drowning and submersion'. Since drowning accounts for the majority of the fatalities from floods, and, to a lesser extent, storms (Jonkman and Kelman 2005), deaths from drowning may naturally increase in the event of flash floods and coastal floods.

Figure 6 presents the relationships between the HDI and hydro-meteorologicalrelated deaths by age groups (i.e. aged $<15$ years, $15-44$ years and $\geq 45$ years) and gender. We observe a strong negative correlation between hydro-meteorological disaster mortality and the HDI that holds across all age groups. With respect to gender, we find that although mortality rates are higher for men than for women, the speed of change for males is, on average, faster. Thus, we expect that differences by gender will become narrower across countries as human development increases.

In order to statistically quantify the relationship between hydro-meteorological disaster mortality and the HDI, we estimate a first-difference type model, with indicator variables for age groups and sex:

$$
\begin{aligned}
\left(d_{i a, t}-d_{i a, t-1}\right)= & B_{0}+B_{1}\left(\mathrm{HDI}_{i a, t}-\mathrm{HDI}_{i a, t-1}\right)+B_{2} I_{\mathrm{F}}+B_{3} I_{\mathrm{F}}\left(\mathrm{HDI}_{i a, t}-\mathrm{HDI}_{i a, t-1}\right) \\
& +B_{4} I_{0-15}+B_{5} I_{0-15} \mathrm{HDI}_{i a, t}+B_{6} I_{45+}+B_{7} I_{45+} \mathrm{HDI}_{i a, t}+e
\end{aligned}
$$

where $d_{i a, t}$ is the hydro-meteorological disaster death rate (per 1000 people) for country $i$, population subgroup $a$ (age and sex), at time $t$. $I_{\mathrm{F}}$ is a dummy variable for females, $I_{0-15}$ is a dummy variable for age group $0-15$, and $I_{45+}$ is a dummy variable for the age group 45 and above. Death rates were computed using data on mid-period population size as the denominator. These data come from the World Population Prospects: the 2012 Revision (United Nations 2013). Table 1 presents the results from the first-difference estimator of mortality rates from floods and storms, controlling for changes in the level of HDI. 
Table 1:

First-difference estimates of mortality rate $(\times 1000)$ from meteorological disasters given changes in the Human Development Index. The model is estimated using data from ICD-7, ICD-8, ICD-9, and ICD-10 for 81 countries, for the period 1970-2010

\begin{tabular}{lll}
\hline Variable & Coefficient estimate & $\boldsymbol{p}$-value \\
\hline Intercept & $-0.0098^{*}$ & 0.0188 \\
Difference in HDI & $-0.7380^{* * *}$ & 0.0000 \\
Female & +0.0011 & 0.1155 \\
Female $\times$ Difference in HDI & $+0.5550^{* * *}$ & 0.0000 \\
Age 0-15 & +0.0047 & 0.4299 \\
Age 0-15 $\times$ HDI & -0.0060 & 0.4422 \\
Age 45+ & -0.0056 & 0.3336 \\
Age 45+ $\times$ HDI & +0.0060 & 0.4666 \\
\hline
\end{tabular}

Note: The data used for this analysis include the following causes of death: victim of cataclysmic storm, all places (ICD-10: X37); victim of cataclysmic flood, all places (ICD-10: X38); accidental drowning and submersion (ICD7: A146; ICD9: B521,C096; ICD10: 1098); accident caused by fire and explosion of combustible material (ICD7: A143); accidents due to natural and environmental factors (ICD9: B520, C095).

We found the coefficients $B_{1}$ and $B_{3}$ to be highly significant. These results confirm our observations based on visualisations of trends in Figure 7. There is a strong negative relationship between the mortality rate and the HDI. The slope is less steep for women than for men. The estimated coefficients for age groups are not statistically significant. However, we observe that the coefficient for the interaction of age group 0-15 and the HDI is negative, whereas the coefficient for the age group $45+$ is positive. These findings may be interpreted as showing that mortality patterns are shifting with development: as development increases, disaster mortality rates may be expected to decrease at a faster pace for children than for the elderly, relative to the adult population.

It is important to highlight that the statistical analysis that we presented is intended to provide a quantitative summary of the trends observed in Figure 6. Using a first-difference model allows us to account for individual country effects. However, there are a number of limitations that we would like to acknowledge. The adjusted $\mathrm{R}^{2}$ for the first-difference model is quite small, at $2 \%$. This indicates that the ability of the model to explain the variance in the data is quite limited. As we described above, our analysis relies on data for ICD classifications 7, 8, 9, and 10. Classifications based on $\operatorname{ICD} 7,8$, and 9 do not include a clear distinction between hydro-meteorological mortality and other related causes of death, like drowning. Therefore, we might be overestimating the effect of development on hydro-meteorological mortality. We ran the same model (described in equation 2) on data from ICD-10 only for countries and years with HDI values greater than 0.7. We observed that from a qualitative point of view, there is still a negative 
Figure 7:

Absolute differences in the number of meteorological deaths reported by WHO and EM-DAT when there were $<10$ deaths per single disaster event

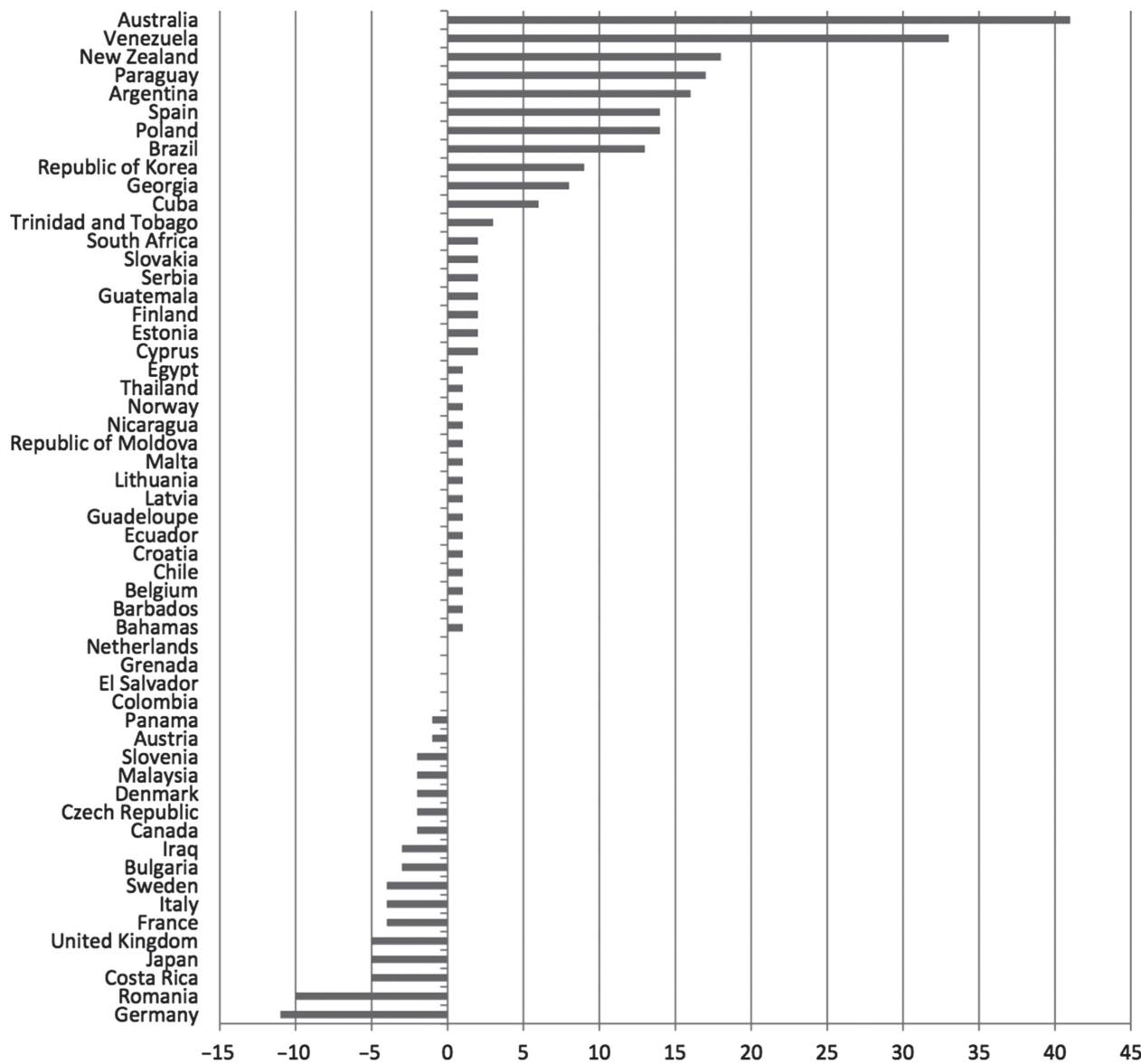

relationship between mortality and HDI values, and between first differences in mortality and first differences in HDI values. However, none of the coefficients in our regression model are statistically significant. The lack of statistical significance is likely to be related to the reduced sample size. Moreover, as we discuss in the next sections, estimates of mortality rates from floods and storms in the WHO ICD10 database tend to underestimate mortality more for relatively low HDI levels. As the underestimation is potentially greater for low HDI levels, a regression analysis that is based on ICD-10 data only may be expected to generate a flatter and less significant slope for the relationship between hydro-meteorological mortality and HDI values. We felt that including additional data sources would be sensible in this situation. However, it is important to be aware that adding more data sources could lead to an overestimation of the effect of development on hydro-meteorological 
mortality. In sum, we cannot provide definitive evidence regarding the relationship between development and meteorological disaster mortality. Nonetheless, we hope that our analysis represents a first step in that direction. Further research with additional datasets is needed to consolidate our initial findings.

\section{Validating deaths from hydro-meteorological disasters estimated from the WHO database}

To our knowledge, this is the first time the WHO mortality database has been used to estimate age-sex differentials in deaths from hydro-meteorological disasters. However, since the WHO mortality data are based on cause-of-death statistics obtained from country civil registration systems, fatalities from natural disasters might be undercounted, especially deaths that are only indirectly related to floods and storms, such as fatal car accidents, heat stroke, heart attacks, or other conditions associated with a lack of medical supplies; unsafe conditions; or a disruption of usual services. Such deaths are typically not linked to the original disaster in countries' civil registration systems. In this section, we compare the aggregated number of deaths from floods and storms reported by the WHO with those recorded by the EM-DAT over the period 1995-2011 for each country with available data.

Figure 7 presents the differences in the absolute number of hydro-meteorological disaster-related deaths reported by the WHO and the EM-DAT when deaths in the WHO database were $<10$. In most countries ( 34 countries), the number of fatalities from floods and storms identified was greater in the WHO database than in the EM-DAT. In 17 countries, the number of flood- and storm-related deaths was found to be higher in the EM-DAT data, but the difference in most countries (15 countries) was no greater than five deaths in absolute terms. The number of fatalities was the same in the WHO database and the EM-DAT for four countries: Colombia, El Salvador, Grenada, and the Netherlands.

On the other hand, in cases of 10 or more reported deaths, the differences between the WHO and EM-DAT data are in the opposite direction. Table 2 presents a list of countries with $\geq 10$ deaths per disaster event from meteorological disasters, including the percentage difference between the number of deaths reported by the WHO and the EM-DAT data sources. Except for Canada, the numbers of deaths from floods and storms reported by the WHO over the period 1995-2011 were monotonously lower than the numbers reported by the EM-DAT for the remaining 35 countries. The percentage differences ranged from as small as $-7.0 \%$ to $-99.9 \%$.

Deaths from low-impact meteorological disasters were undercounted by the EMDAT due to the nature of the CRED's data collection procedures. One criterion used by the CRED for determining whether an event qualified as a disaster is that 10 or more people are killed in a particular event. Thus, based on this definition, small disaster events are underrepresented in the EM-DAT database. 
Table 2:

Number of deaths from floods and storms reported by WHO and EM-DAT over the period 1995-2011 for each disaster event with $\geq 10$ deaths in WHO database

\begin{tabular}{|c|c|c|c|}
\hline Country & WHO & EM-DAT & $\%$ difference \\
\hline Canada & 12 & 11 & 9.1 \\
\hline Slovakia & 50 & 54 & -7.4 \\
\hline United Kingdom & 9 & 10 & -10.0 \\
\hline Panama & 13 & 16 & -18.8 \\
\hline Paraguay & 25 & 33 & -24.2 \\
\hline Cuba & 15 & 20 & -25.0 \\
\hline Republic of Korea & 708 & 1439 & -50.8 \\
\hline United States of America & 1895 & 3958 & -52.1 \\
\hline Grenada & 18 & 39 & -53.8 \\
\hline Czech Republic & 27 & 64 & -57.8 \\
\hline France & 63 & 161 & -60.9 \\
\hline Japan & 314 & 874 & -64.1 \\
\hline Argentina & 38 & 133 & -71.4 \\
\hline Australia & 12 & 55 & -78.2 \\
\hline Poland & 9 & 46 & -80.4 \\
\hline Guatemala & 306 & 1571 & -80.5 \\
\hline Philippines & 509 & 2678 & -81.0 \\
\hline Brazil & 263 & 1447 & -81.8 \\
\hline Spain & 11 & 62 & -82.3 \\
\hline Germany & 17 & 100 & -83.0 \\
\hline Malaysia & 12 & 76 & -84.2 \\
\hline Haiti & 11 & 88 & -87.5 \\
\hline Mexico & 233 & 1967 & -88.2 \\
\hline Romania & 26 & 238 & -89.1 \\
\hline Dominican Republic & 37 & 347 & -89.3 \\
\hline Portugal & 4 & 46 & -91.3 \\
\hline Colombia & 43 & 506 & -91.5 \\
\hline Austria & 1 & 12 & -91.7 \\
\hline Sri Lanka & 2 & 25 & -92.0 \\
\hline Thailand & 50 & 727 & -93.1 \\
\hline Peru & 4 & 82 & -95.1 \\
\hline Nicaragua & 166 & 3601 & -95.4 \\
\hline South Africa & 8 & 186 & -95.7 \\
\hline Bulgaria & 1 & 39 & -97.4 \\
\hline El Salvador & 1 & 275 & -99.6 \\
\hline Venezuela & 39 & 30117 & -99.9 \\
\hline
\end{tabular}


Figure 8:

Relationships between percentage differences in hydro-meteorological deaths reported by WHO and EM-DAT when deaths were $\geq \mathbf{1 0}$ per single disaster event and HDI. Pearson's $r=0.374, p=0.025$

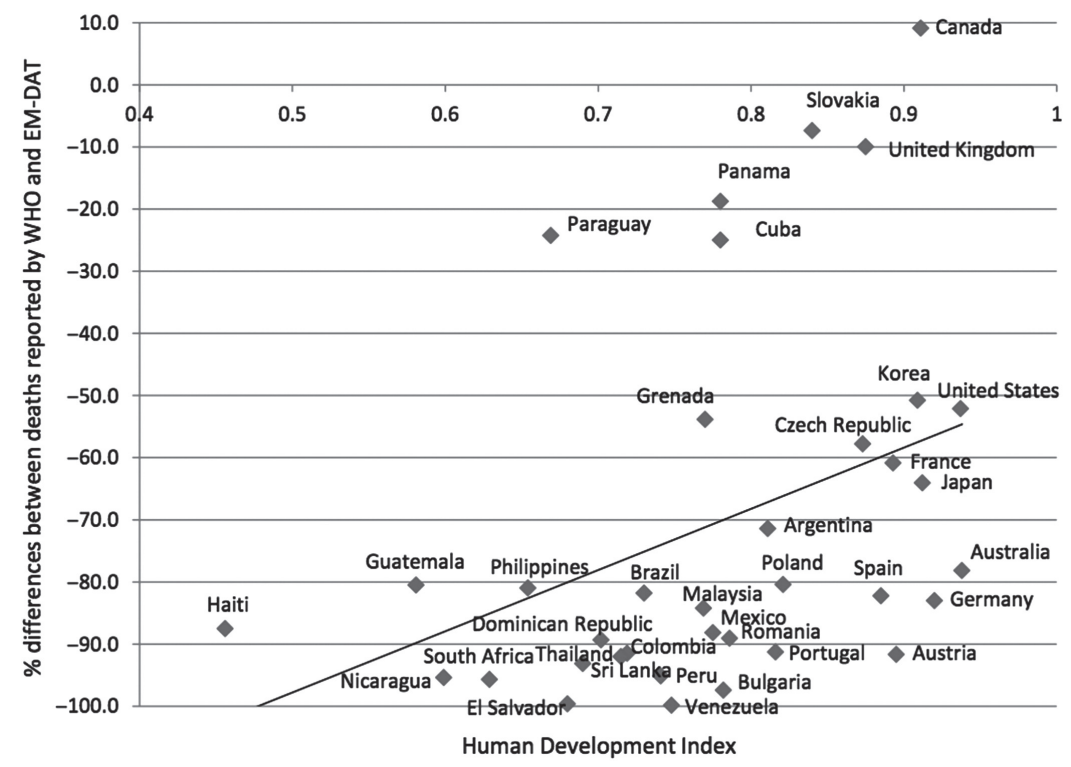

On the other hand, we find that in the WHO database the numbers of deaths from high-impact disaster events are systematically lower. While the WHO mortality database relies on civil registration data from the respective national authorities, the CRED obtains death estimates from various sources, both official and non-official. The number of fatalities might be overestimated or underestimated for a number of reasons, such as in order to attract international assistance or to cover up disaster management failures. Another reason for the discrepancy between the WHO and the EM-DAT data is related to how missing persons (i.e. people whose bodies were not recovered) are recorded. In some disaster events this number can be very high, but unlike the CRED, the WHO database does not include these cases.

One extreme example of a discrepancy between the numbers of deaths recorded by the WHO database and the EM-DAT is the case of Venezuela: for this country, the EM-DAT reported 30,117 deaths from hydro-meteorological disasters, whereas the WHO database reported only 37 deaths. This enormous gap between the two datasets is due to a single storm event in December 1999, in which heavy rainfall triggered thousands of landslides on steep slopes of the Sierra de Avila north of Caracas, as well as flooding and massive debris flows in the State of Vargas along the Caribbean coast. The early estimated death toll was between 5,000 and 50,000, while the figure that is now generally recognised as accurate is around 30,000 (the number recorded by the EM-DAT) (Wieczorek et al. 2001). The WHO database 
does not report the deaths of people who were buried in the landslides or swept away to sea by the mud, debris flows, and flooding, since the vast majority of bodies were never recovered, and were therefore not registered as deaths in the standard vital registration system. Moreover, an accurate assessment of the exact number of people who perished was impossible due to the lack of recent census figures for Vargas in the period before the disaster event.

In developed countries with much better civil registration and vital statistics systems (Mahapatra et al. 2007), it is possible that the discrepancies in the numbers of fatalities reported by the WHO mortality database and the EM-DAT are smaller. Accordingly, we display in Figure 8 a scatterplot of the relationship between the HDI and the percentage differences between the number of deaths reported by the WHO database and the EM-DAT over the period 1995-2011. The relationship between the two factors is significant and positive (Pearson's $r=0.374, p=0.025$ ). This suggests that the higher the HDI, the smaller the discrepancy between the numbers of fatalities documented in the WHO database and the EM-DAT.

\section{Discussion}

Using the age- and sex-specific cause-of-death data from the WHO cause-ofdeath mortality database, we estimated patterns of differential hydro-meteorological disaster mortality, as well as their relationships with levels of societal development. The first objective of the study was to describe age-sex differentials in mortality patterns from floods and storms. We observed heterogeneous patterns of mortality that could be summarised in the spirit of model life tables as constituting three main families. In some countries, children and the elderly—and especially girls and older women-were the most affected groups. In other countries, male adults were at highest risk of death from meteorological disasters.

When focusing on the aggregated number of flood- and storm-related deaths by sex, we found that in almost all countries male fatalities were higher than female fatalities. This finding contradicts previous results on deaths from natural disasters by Neumayer and Plümper (2007), who reported that more women were killed than men, and that women were killed at younger ages than men. Apart from the fact that we only considered flood and storm events while Neumayer and Plümper included all types of natural disasters, our study estimated mortality by gender directly using sex-specific death records from the WHO mortality database, whereas Neymayer and Plümper estimated sex-specific fatalities using data on the gender gap in life expectancy, while taking into account the intensity of each disaster. Hence, it is plausible that women are not always more vulnerable to natural disasters than men, especially in the context of disasters such as floods and storms, in which men are more likely than women to engage in active risk-taking behaviour, and to be exposed to the disaster. For example, the fact that men are more likely to be engaged in outdoor work or leisure activities than women (Bradshaw 2004) could play a role 
in determining mortality. In contrast, in sudden-onset disasters like earthquakes or tsunamis, mortality tends to be higher among women than men.

The second important goal of our study was to investigate the relationship between development and disaster mortality, and how this relationship differs by age and gender. Consistent with previous studies (Patt et al. 2010; Striessnig et al. 2013), we found a strong negative relationship between mortality and development, as measured by the HDI. Our study further adds to extant findings that the decline in mortality rates from hydro-meteorological disasters occurred at a faster pace for men than for women. Meanwhile, we found no strong evidence that the speed of the reduction in mortality rates, given a change in the HDI, differed between age groups. Our finding that the mortality reduction corresponding to improvements in the HDI was greater for men than for women could be due to unequal access to resources, whereby men were able to benefit more than women from socioeconomic development (Denton 2002; Nelson et al. 2002). This result could also be related to the fact that mortality rates from meteorological disasters were simply higher for men than for women, which implies that there is more room for improvement for men than for women.

The finding that countries that are more developed, as measured by the HDI, tend to experience lower levels of disaster mortality suggests that development could play a key role in reducing vulnerability to natural disasters. The factors that drive development (e.g. health, education, income) tend to be protective factors against disasters as well. However, the whole chain of causal relationships is not completely clear. More educated people may have a better understanding of the risks associated with disasters than their less educated counterparts (Muttarak and Lutz 2014, Lutz et al. 2014). People with higher socio-economic status may have more resources to protect themselves or to escape from disaster-prone areas than those with lower status (Fussell et al. 2010). Richer societies may have means to prepare for disasters and to co-ordinate interventions that poorer societies lack (Kahn 2005). Being in good health could increase the probability of survival during disastrous events (Brooks et al. 2005). Moreover, levels of exposure to the risks associated with disasters may be lower in more developed countries than in less developed countries. Regardless of the specific mechanisms at play, from a policy perspective it is important to consider development as one of the tools for enhancing the capacity of societies to adapt to future climate change, and to the more frequent extreme weather events that are expected to result from climate change.

Using the WHO mortality database, we were able to identify which demographic groups are more vulnerable to meteorological disasters, and whether the impact of development on disaster-mortality reduction varies between gender and age groups. However, the WHO data are not without limitations. First, although the WHO mortality database is the most respected official source for comparative analyses we are aware of, the sample of countries is biased. Developing countries with poor or non-existing civil registration systems are not represented, and our results should not be generalised to those countries. Indeed, it has been shown that flood and storm mortality is concentrated in the less developed and heavily populated 
nations of southeast Asia and the western Pacific (Doocy et al. 2013a, 2013b), where WHO data are scarcely available. The demographic differentials in flood- and storm-related mortality observed in this study could thus be biased. For instance, if women are more likely to die from hydro-meteorological disasters in less developed countries, our analysis would not have been able to capture such a mortality pattern.

Second, since the age- and sex-specific cause-of-death data provided by the WHO are obtained from civil registration systems, the number of fatalities from hydrometeorological disasters may have been undercounted owing to 1) how the cause of death was identified and 2) whether there were large numbers of missing persons associated with a disaster event. Indeed, our validation procedures for comparing the numbers of fatalities reported by the WHO with those reported by the EMDAT showed that, especially in high-impact disaster events, the WHO database systematically reported lower numbers of deaths than the EM-DAT. If this bias in disaster mortality was distributed evenly across population subgroups, our analysis of age-sex differentials in mortality patterns would still be valid, since our interest was in demographic profiles of deaths rather than the absolute numbers of deaths per se. Given the lack of other global data sources, we were unable to directly test if this was the case. It should be noted that it is also possible that deaths were underreported in the EM-DAT for some countries, especially those in Africa where data reporting is poor (Guha-Sapir and Hoyois 2012). If this is the case, the true number of fatalities from floods and storms identified in the WHO mortality database would be even lower than our estimates.

Third, although mortality is an indicator of disaster impact that is directly measurable, fatalities from natural disasters have become more preventable with social and economic development, and disaster-related mortality has declined over time (Goklany 2009). Subsequently, in the absence of high-impact disasters, mortality might not be a valid indicator of natural disaster impacts. In addition to having direct effects, floods have a number of indirect effects, including morbidity and livelihood disruption, which may be associated with additional, unaccounted mortality. Although these indirect effects are important, they are less important than the direct effects. Direct mortality, like mortality related to drowning, accounts for the great majority of fatalities from hydro-meteorological disasters. Non-mortality measures, like economic damage or injuries, could also be considered. However, measures such as economic losses may be strongly dependent on the level of GDP of specific countries, and these kinds of estimates tend to be inexact (Downton and Pielke 2005). Estimates of direct mortality are, by contrast, more precise. Moreover, we can assume that societies around the world attach considerable value to human life, although differences may exist. Therefore, the number of deaths is an appropriate indicator for comparative analyses. 


\section{Conclusion}

Understanding the relationships between demographic differential vulnerability and socio-economic development helps us assess the potential impact of climate change on mortality, and how that impact differs at various stages of development for countries in different regions of the world. This information is important because it allows us to evaluate the potential capacity of societies to cope with climate change in the future, and to identify the groups within a population who are at greater risk of suffering from the consequences of climate change.

Our study has shown that flood- and storm-related fatalities can follow different patterns across the globe. One pattern indicates that mortality risks are higher among young children and the elderly, and especially among females; while another pattern shows that mortality risks are higher among young adult males. Documenting the differences across countries can help us understand why some groups are at a greater disadvantage in some countries than in others. Our results also suggest that the reductions in disaster-related mortality that generally accompany improvements in the HDI are not distributed evenly between men and women. Understanding the social, economic, and geographic factors that explain the differential impact of disasters could help to reduce the unequal distribution of the consequences of climate change.

In addition to the substantive results discussed in the paper, this article highlights the limitations of currently existing datasets and the importance of combining all available data sources in order to improve our understanding of the differential demographic impact of natural disasters. We presented novel findings, but we also acknowledged the substantial uncertainty associated with the data. We hope that this article will stimulate further research with additional datasets that will help us gain a better understanding of the heterogeneous demographic impact of natural disasters.

\section{Acknowledgements}

Funding for this work was made possible by an Advanced Grant of the European Research Council, 'Forecasting Societies Adaptive Capacities to Climate Change' (grant agreement ERC-2008-AdG 230195-FutureSoc). We would like to thank the two reviewers and the editor for their insightful comments that helped us improve the manuscript substantially.

\section{References}

Ahern, M., R. S. Kovats, P. Wilkinson, R. Few and F. Matthies 2005. Global health impacts of floods: Epidemiologic evidence. Epidemiologic Reviews 27: 36-46.

Alderman, K., L. R. Turner and S. Tong 2012. Floods and human health: A systematic review. Environment International 47(October): 37-47. 
Ashley, S. T. and W. S. Ashley 2008. Flood fatalities in the United States. Journal of Applied Meteorology and Climatology 47(3): 805-18.

Bern, C., J. Sniezek, G. M. Mathbor, M. S. Siddiqi, C. Ronsmans, A. M. Chowdhury, A. E. Choudhury, K. Islam, M. Bennish and E. Noji 1993. Risk factors for mortality in the Bangladesh cyclone of 1991. Bulletin of the World Health Organization 71(1): 73-78.

Bradshaw, S. 2004. Socio-economic impacts of natural disasters: A gender analysis. Serie Manuales 33. Santiago de Chile: United Nations Economic Commission for Latin America and the Caribbean.

Brooks, N., W. N. Adger and P. M. Kelly 2005. The determinants of vulnerability and adaptive capacity at the national level and the implications for adaptation. Global Environmental Change, Adaptation to Climate Change: Perspectives Across Scales 15(2): 151-63.

Brunkard, J., G. Namulanda and R. Ratard 2008. Hurricane Katrina deaths, Louisiana, 2005. Disaster Medicine and Public Health Preparedness 2(4): 215-23.

Byrnes, J. P., D. C. Miller and W. D. Schafer 1999. Gender differences in risk taking: A meta-analysis. Psychological Bulletin 125(3): 367-83.

Chowdhury, A. M., A. U. Bhuyia, A. Y. Choudhury and R. Sen 1993. The Bangladesh cyclone of 1991: Why so many people died. Disasters 17(4): 291-304.

Clark, S. J. 2015. A singular value decomposition-based factorization and parsimonious component model of demographic quantities correlated by age: Predicting complete demographic age schedules with few parameters. 143. University of Washington Center for Statistics and the Social Sciences (CSSS) Working Paper. Seattle: University of Washington Center for Statistics and the Social Sciences. http://arxiv.org/abs/1504.02057.

Coates, L. 1999. Flood fatalities in Australia, 1788-1996. Australian Geographer 30(3): 391-408.

Croson, R. and U. Gneezy 2009. Gender differences in preferences. Journal of Economic Literature 47(2): 448-74.

Denton, F. 2002. Climate change vulnerability, impacts, and adaptation: Why does gender matter? Gender and Development 10(2): 10-20.

Doocy, S., A. Dick, A. Daniels and T. D. Kirsch 2013a. The human impact of tropical cyclones: A historical review of events 1980-2009 and systematic literature review. PLoS Currents 5(April). doi:10.1371/currents.dis.2664354a5571512063ed29d25ffbce74.

Doocy, S., A. Daniels, S. Murray and T. D. Kirsch 2013b. The human impact of floods: A historical review of events 1980-2009 and systematic literature review. PLoS Currents 5(April). doi:10.1371/currents.dis.f4deb457904936b07c09daa98ee8171a.

Downton, M. W. and R. A. Pielke 2005. How accurate are disaster loss data? The case of U.S. flood damage. Natural Hazards 35(2): 211-28.

EM-DAT, CRED 2010. The OFDA/CRED International Disaster Database. Brussles, Belgium: Université Catholique de Louvain, Center for Research on the Epidemiology of Disasters (CRED). http://www.em-dat.net.

Fankhauser, S. and T. K. J. McDermott 2014. Understanding the adaptation deficit: Why are poor countries more vulnerable to climate events than rich countries? Global Environmental Change 27(July): 9-18.

FitzGerald, G., W. Du, A. Jamal, M. Clark and X.-Y. Hou 2010. Flood fatalities in contemporary Australia (1997-2008). Emergency Medicine Australasia 22(2): 180-86. 
Fussell, E., N. Sastry and M. VanLandingham 2010. Race, socioeconomic status, and return migration to New Orleans after hurricane Katrina. Population and Environment 31(1-3): 20-42.

Goklany, I. M. 2009. Deaths and death rates from extreme weather events: 1900-2008. Journal of American Physicians and Surgeons 14(4): 102-9.

Guha-Sapir, D. and P. Hoyois 2012. Measuring the human and economic impact of disasters (commissioned review), Foresight, Government Office for Science. Foresight, London. https://www.gov.uk/government/uploads/system/uploads/attachment_data/file/ 286966/12-1295-measuring-human-economic-impact-disasters.pdf.

Guha-Sapir, D., P. Hoyois and R. Below 2013. Annual Disaster Statistical Review 2012: The Numbers and Trends. Brussels: CRED. http://cred.be/sites/default/files/ADSR_2012.pdf.

INDEPTH Network 2004. Indepth Model Life Tables for Africa: For Sub-Saharan Africa. Aldershot, Hants, England; Burlington, VT: Ashgate Publishing Limited.

IPCC (Intergovernmental Panel on Climate Change) 2007. Climate change 2007: The physical science basis: Contribution of working group I to the fourth assessment report of the Intergovernmental Panel on Climate Change. Cambridge: Cambridge University Press.

Jonkman, S. N. and I. Kelman 2005. An analysis of the causes and circumstances of flood disaster deaths. Disasters 29(1): 75-97.

Jonkman, S. N., B. Maaskant, E. Boyd and M. L. Levitan 2009. Loss of life caused by the flooding of New Orleans after hurricane Katrina: Analysis of the relationship between flood characteristics and mortality. Risk Analysis: An Official Publication of the Society for Risk Analysis 29(5): 676-98.

Kahn, M. E. 2005. The death toll from natural disasters: The role of income, geography, and institutions. The Review of Economics and Statistics 87(2): 271-84.

Lee, R. D. and L. R. Carter 1992. Modeling and forecasting U.S. mortality. Journal of the American Statistical Association 87(419): 659-71.

Lutz, W., R. Muttarak and E. Striessnig 2014. Universal education is key to enhanced climate adaptation. Science 346(6213): 1061-62.

Mahapatra, P., K. Shibuya, A. D. Lopez, F. Coullare, F. C. Notzon, C. Rao and S. Szreter 2007. Civil registration systems and vital statistics: Successes and missed opportunities. The Lancet 370(9599): 1653-63.

Muttarak, R. and W. Lutz 2014. Is education a key to reducing vulnerability to natural disasters and hence unavoidable climate change? Ecology and Society, Education and Differential Vulnerability to Natural Disasters 19(1): 42.

Myung, H.-N. and J.-Y. Jang 2011. Causes of death and demographic characteristics of victims of meteorological disasters in Korea from 1990 to 2008. Environmental Health 10(1): 82.

Nelson, V., K. Meadows, T. Cannon, J. Morton and A. Martin 2002. Uncertain predictions, invisible impacts, and the need to mainstream gender in climate change adaptations. Gender and Development 10(2): 51-59.

Neumayer, E. and T. Plümper 2007. The gendered nature of natural disasters: The impact of catastrophic events on the gender gap in life expectancy, 1981-2002. Annals of the Association of American Geographers 97(3): 551-66. 
Nicholls, R. J. 2004. Coastal flooding and wetland loss in the 21st century: Changes under the SRES climate and socio-economic scenarios. Global Environmental Change, Climate Change 14(1): 69-86.

Patt, A. G., M. Tadross, P. Nussbaumer, K. Asante, M. Metzger, J. Rafael, A. Goujon and G. Brundrit 2010. Estimating least-developed countries' vulnerability to climate-related extreme events over the next 50 years. Proceedings of the National Academy of Sciences 107(4): 1333-37.

Pradhan, E. K., K. P. West Jr., J. Katz, S. C. LeClerq, S. K. Khatry and S. R. Shrestha 2007. Risk of flood-related mortality in Nepal. Disasters 31(1): 57-70.

Shultz, J. M., J. Russell and Z. Espinel 2005. Epidemiology of tropical cyclones: The dynamics of disaster, disease, and development. Epidemiologic Reviews 27(1): 21-35.

Striessnig, E., W. Lutz and A. G. Patt 2013. Effects of educational attainment on climate risk vulnerability. Ecology $\mathcal{E}$ Society $18(1)$.

Thacker, M. T. F., R. Lee, R. I. Sabogal and A. Henderson 2008. Overview of deaths associated with natural events, United States, 1979-2004. Disasters 32(2): 303-15.

Toya, H. and M. Skidmore 2007. Economic development and the impacts of natural disasters. Economics Letters 94(1): 20-25.

United Nations 2013. World population prospects: The 2012 revision. Key findings and advance tables. New York, NY: Department of Economic and Social Affairs, Population Division. http://esa.un.org/unpd/wpp/Documentation/publications.htm.

Wieczorek, G. F., M. C. Eaton, B. A. Morgan and J. L. Blair 2001. Debris-Flow and flooding hazards associated with the December 1999 storm in coastal Venezuela and strategies for mitigation, 01-0144. Reston, VA: U.S. Geological Survey. 